\title{
The Negative Effects Caused by the Development of the Painting and Calligraphy Market during the Early Period of the Republic of China (1912-1937)
}

\author{
TAO Xiaojun \\ College of Cultural Industries, Nanjing University of the Arts \\ WANG Hangwei \\ School of Fine Arts, Nanjing Normal University
}

\begin{abstract}
Under the influence of the whole economic situation, the painting and calligraphy market developed greatly during the early period of the Republic of China, which improved the survival situation and social status of the painters and calligraphers, but which objectively brought negative effects on the progress of the art as well. Driven by profits, the painters and calligraphers made their creation modeled and taskoriented, and the heavy task of selling art left them no time to give enough consideration to the quality of art. What's more, the value standard of painting and calligraphy started to be shaken by the further-deepening of the market, more and more non-artistic factors exerted influences on the creation of the painters and calligraphers. In addition, the desire of reaping the rewards as soon as possible made it a common practice in the art circle to imitate those big-timers, which, as a result, killed the creativity most important to the art, and caused the disastrous effects which can never be neglected.
\end{abstract}

KEYWORD: the early period of the Republic of China; the painting and calligraphy market; negative effects

\section{PART ONE}

It is an undeniable fact that the development of the painting and calligraphy market stimulated the competition among the painters and calligraphers during the early period of the Republic of China, which caused many talented painters and calligraphers to make continuous explorations and innovations so as to have a larger market. On the other hand, however, to the big-timers and the painters and calligraphers driven by material benefits, the utilitarian market-oriented business model brought about undoubted bad effects.

The first change the market brought to the painters and calligraphers, especially those professional ones, was the sudden expansion of the workload. Such a phenomenon already appeared as early as at the end of the Qing Dynasty, when the marketization made some progress. For example, when Ren Bonian created his paintings, he was often urged by art dealers, and, therefore, "gave more priority to speed, and made painting something like today's assembly line ... Moreover, he might paint peach blossoms and swallows for one day and Chinese bulbuls for another", and his studio "was filled with his paintings" (Zheng, 2005a: 7). And Pu Hua "tried to contend for his 'domain', never changed his style, granted whatever was requested even for a low pay, and the number of his paintings was extremely large" (Zhu, 1999: 36). During the Early Period of the Republic of China, such a situation did not disappear but rather turned more serious. Wu Changshuo had to work for three months at the speed of three paintings a day to finish creating the requested paintings in the last year.

It was not the heavy workload but lack of freedom caused by dealings that had the greatest effects on the quality of art of painters and calligraphers. The buyers could make all kinds of requests on the creation of painters and calligraphers.

Such requests were based on the buyers' mundane aesthetical standards, and most of the painters and calligraphers who were in a weak position had to listen to the buyers' requests. Wu Changshuo had a strong literati complex, and disliked such common flowers as peonies, narcissus, etc. He once wrote a poem satirizing peonies, "The national beauty and heavenly fragrance ${ }^{1}$ has very beautiful appearance, and blossoms when Guyu ${ }^{2}$ comes in late spring; as a flower of wealth, it is so much envied, but it never bears fruits" (Wu, 2006: No. 0136). In another poem satirizing narcissus, Wu said, "In the kingdom of fragrance, it is known as the queen of flowers, and

\footnotetext{
1 The national beauty and heavenly fragrance is often referred to as a peony.

2 The $6^{\text {th }}$ solar term.
} 
with so many green leaves supporting, it is more outstanding than all the others; despite a beautiful name, of which it is really unworthy, it is less beautiful than a species of chrysanthemum called Yupaohuang" (Wu, 2011: No. 1458). However, in order to meet the customers' requests, $\mathrm{Wu}$ created many paintings with both peonies and narcissus just because they have the implied meaning of "riches and honors". In a poem, he said with grief and indignation, "Just to earn some bread, I have to get insulted. With tears in my eyes, I can never express my heroism" (cited from Liu et al., 1986: 175). Even such a master could not realize his likes but sigh to the sky, let alone other ordinary painters and calligraphers. However, unfortunately, the restrictions which the customers' special requests set to painters and calligraphers were not only reflected in what should be painted, but also what should not be painted and even how it should be painted. For example, Chao Zhangfu recorded the taboo rules for the customers' special requests which were popular in Shanghai in the early period of the Republic of China:

\begin{abstract}
When painting in order to get paid, the painters lose their freedom; various special requests from the customers set all kinds of restrictions to the painters. The requests are not necessarily what the painters wish to do, not even what they ae good at, and, therefore, what the painters produce cannot necessarily satisfy the buyers' wishes. When painting at ordinary times, the painters have much freedom to paint whatever they wish to. However, we have heard of many superstitious beliefs in Shanghai. For example, if plum blossoms get out of a branch, it means "bad luck"; if plum blossoms and bamboos are painted together, such an elegant painting means "unlucky"; if plum blossoms, bamboos and stones are painted together, it means "extremely unlucky". Painting like this, even with beautiful touches, can never get appreciated. There are so many taboos for the painters. (Chao, 2009: 64)
\end{abstract}

We can imagine that if all buyers order paintings like this, it never means creation to painters. But faced with such orders, the painters always tried to satisfy them. For example, although with a profound and beautiful artistic conception, Wu Daiqiu's paintings have the problem of too much piling up just because "the Shanghainese paid a good price for his paintings with a hope of having more touches, so he had to paint like that" (Zhang, 1964: 246). In order to occupy the market, some painters even offered to abandon themselves to the worldly value and to meet the tastes of the marketplace.

We don't mean to belittle the mundane aesthetical orientation, but to emphasize the fact that the attitude to blindly yield to any request of buyers had obvious effects on painters and calligraphers' passion for creation. Moreover, the creation pattern of unthinkingly accepting any request from buyers stifled the painters and calligraphers' quality consciousness and innovation consciousness. For instance, on a trip out, Feng Chaoran said to his student Lu Yanshao, "I've formed such a style, which is required by the buyers and can't be changed. If I make innovations and change my style, they will say that somebody else does that on my behalf or that the painting is a fake, and will refuse to pay me" ( $\mathrm{Si}, 2008: 66)$.

When confronted with the pressure from buyers, some painters and calligraphers made various kinds of opposition. For example, "Wu Hufan disliked the buyers' making requests on the style of his creation when he created his paintings. If asked for an ink and wash painting, he would fill in colors on the painting; but if asked to fill in colors on the painting, he would create an ink and wash painting. If someone asked him to paint something by imitating someone else, $\mathrm{Wu}$ would write back: now that you know it so well, why don't you do it in person!" (Zheng, 2005b: 56).

However, we have to know that Wu Hufan was born into a family of a government official and, therefore, had very good financial support. Most of the painters and calligraphers who made their living by selling art did not have the courage to say no to their customers. Under such circumstances, the decline in the artistic quality of the paintings became unavoidable.

\section{PART TWO}

In the brisk market, the mundaneness had effects not only on the painters and calligraphers' creation process, but also on the end products and on the value standards of the painters and calligraphers' established art features and styles. The number of painting and calligraphy buyers during the early period of the Republic of China was remarkably larger than in the Qing Dynasty. But many buyers, especially the emerging bourgeois, businessmen, and rich families, bought paintings and calligraphy in order to be arty-crafty or to show off.

Even some rich businessmen and returned students in large cities pretended to be artistic by hanging one or two paintings by $\mathrm{Wu}$ Changshuo or Wang Yiting, thinking that they were necessary furnishings at home to show off in the presence of foreigners. But they hardly realized that there were some foreigners who knew better about paintings than them. (Luo, 1997: 122) 
Buying paintings with the purpose of "showing off" and "being arty-crafty" widened the difference between the artistic level and the value of painting and calligraphy. And the social position of the creators got more and more important. A good case in point is the popularity of celebrities' works of painting and calligraphy.

Although the celebrities were not well accomplished, their works were widely accepted in the society because of their social influences. Such a practice became popular in the market of painting and calligraphy, and those professional painters and calligraphers without a good background also found the advantages of fame. "If a painter becomes famous, his paintings will spread like wildfire and fly without wings, and a piece of paper will earn a lot of money" (Yu, 2009: 29).

Some painters and calligraphers enjoyed a great number of social resources and became famous at that time, but they turned out to be a flash in the pan, leaving nothing in the history of fine arts. Some others, who were plain, tried to seek a higher artistic state, and had super skills, but their works didn't get fair evaluation.

Meanwhile, some other excellent painters and calligraphers who lacked social popularity either tolerated poverty with a persistent belief in art, or was forced by life to give up seeking the high artistic state, which was undoubtedly very bad to the development of the art of painting and calligraphy.

Apart from the effects of social popularity on the value of painting and calligraphy, the distortion of the value of painting and calligraphy was reflected in other aspects. With the market becoming prosperous and the intermediary agents becoming active, the buying of painting and calligraphy for the purpose of investment became increasingly popular, which resulted in endless malignant hype. When asked about the source of his assumed name "Bailongshanese", Wang Yiting said that he had made so many friends, that his friends from all walks of life came to ask him for a painting, that many of them didn't pay him, that he felt embarrassed to ask them for pay, and that "Bailongshanese" meant "Bainongshanese" 3 . Of course, Wang Yiting was kidding when he gave such an explanation. But ridiculously, after his remark got spread in the society, Wang Yiting's works with the signature of "Bailongshanese" were unexpectedly less expensive than those with the signature of "Wang Zhen from Wuxing" (Liu et al., 1986: 63), because the buyers thought that the "Bainong" works which didn't get paid must have been something the painter didn't work hard on. Even Wang Yiting, who was very

\footnotetext{
3 "Bainong" in "Bainongshanese" means "doing something in vain". By changing "Bailong" to "Bainong", Wang Yiting meant that he painted for some of his friends in vain, i.e. he got no pay from them.
}

experienced in business, didn't expect that a casual remark like that should have led to the fluctuations in price in the market of painting and calligraphy.

During the early period of the Republic of China, it was not uncommon to hype the painting and calligraphy of the dead because after a painter or calligrapher died, his works would "stop production", the number of the works being circulated in the society was fixed, and the more were collected, the less were circulated in the society, which made it easy to bid up the price. Its distortion to the artistic value of painting and calligraphy was most evident. For example, it was a matter of course that Bai Zongwei's works were refused by the market. But because of his death and the hypesters' hoarding, his works became hot treasures in the market of painting and calligraphy. Such a practice undoubtedly treated the works of painting and calligraphy as ordinary commodities, abandoning the spiritual nature of the works of art.

The practice of hyping the painting and calligraphy of the dead has not disappeared. It has even developed into the painters and calligraphers' common sense of the market. For instance, Hu Shiyu once wrote in a poem, "There are fakes for my works even when I am alive, they are bound to have very high value when I am dead" (Zheng, 2005c: 63). Even now, similar practices of hyping are still spreading in the market of painting and calligraphy. If such a situation continues, the artistic level will lose its control over the market, which is destructive to the inheritance of the art of painting and calligraphy. This is true of any historical period.

\section{PART THREE}

The buyers were not the only party who caused the negative effects on the market of painting and calligraphy. Some of the painters and calligraphers were also responsible for them. A typical example is the imitation of those big-timers. The consciousness of innovation is the driving force for the development of art. All those successful painters and calligraphers in the early period of the Republic of China had a strong desire of reform and innovation. Just as Yu Jianhua put it, "If art at any time in any place becomes prosperous, there must be someone who has a unique style of work, pushes aside all difficulties and obstacles, has the spirit of 'getting worried when praised and getting happy when criticized', keeps on fighting in spite of all setbacks, and then overthrows the established old art, builds a new lively art, and brings radiant splendor to the circles of art" (Yu, 2009: 93). On the other hand, however, in the flourishing market, more and more painters and calligraphers give in to the financial needs, and attaches more importance to getting into and occupying the market as soon as possible than to 
innovation, and their simplest practice is to imitate those big-timers.

The problem of imitation in the field of painting and calligraphy in the early period of the Republic of China was not simply an individual's behavior but obviously an atmosphere prevalent in the society. Apart from the successful professional artists like $\mathrm{Wu}$ Changshuo and $\mathrm{Li}$ Ruiqing, the imitators included some celebrities in the circles of politics and business such as $\mathrm{Hu}$ Hanmin, Zheng Xiaoxu, Tan Yankai, Zhang Jian, Yuan Kewen, etc. Of course, they also had some attainments in calligraphy, but their artistic level did not deserve the hot welcome given by calligraphers everywhere. At that time, all the works that had had a high social position in the market became models to be imitated by painters and calligraphers.

In the circles of painting and calligraphy where the inheritance of artistry is attached great importance to, referring to and drawing lessons from the famous artists in the ancient times is a very natural learning strategy. But the imitators in the early period of the Republic of China not only drew lessons from the ancestors, but also copied every detail so as to make their works alike to those imitated, totally losing their own style. That was quite different from the traditional method of learning painting and calligraphy. Therefore, $\mathrm{Yu}$ Jianhua made his sharp comments by saying that "in comparison with the Mogupai School (a school of painting in the Qing Dynasty, imitating the paintings of Dong Qichang), those from this school in the early period of the Republic of China were lower in artistic level, more short-sighted, and humbler in purpose; what they knew and respected were only their own teachers, and they were content with their own paintings looking like their teachers' so that they could have enough money to enjoy themselves throughout their life; and they never knew that there is always someone who is better than us" (Yu, 2009: 28). Such a practice may help painters and calligraphers to obtain quite a lot of achievements within a short period of time, but is destructive to the progress of their artistic level. When talking to his student Chen Julai, Zhao Shuru said, "You'd better specialize in Han Seal instead of imitating me because even if you can imitate every detail of mine, you can never get ahead because of me. You see, $\mathrm{Wu}$ Changshuo has so many students, but none of them gets successful, because they are so alike to $\mathrm{Mr}$. Wu" (Si, 2008: 54). Zhao's remarks have the truth: however alike the imitation is, it is a mere repetition in art and can never surpass those predecessors.

\section{ACKNOWLEDGEMENT}

The writing of this paper is supported by "Jiangsu Provincial Social Science Fund Project in 2013" (The project No. is 13LSB008).

\section{REFERENCES}

[1] Chao, Zhangfu. 2009. On Art in Haitianlou. Beijing: People's Fine Arts Publishing House.

[2] Liu, Haisu. et al. 1986. Recalling Wu Changshuo. Shanghai: Shanghai People's Fine Arts Publishing House.

[3] Luo, Jialun. 1997. A New Outlook of Life. Shenyang: Liaoning Education Press.

[4] Si, Shunwei. 2008. An Exploration of the Century-Long Painting Circle. Shanghai: Oriental Publishing Center.

[5] Wu, Changshuo. 2006. A Picture of Peonies and Rare Stones. In A Special Session of the Works of Ten Masters of Chinese Painting and Calligraphy in Modern Times. Hangzhou: Xiling Yinshe Auction Co., Ltd. No. 0136.

[6] Wu, Changshuo. 2011. Riches and Honors of Peonies. In A Special Session of Wu Changshuo's Works. Beijing: Beijing Kuangshi Auction Co., Ltd. No. 1458.

[7] Yu, Jianhua. 2009. A Collection of Yu Jianhua's Papers on the History of Fine Arts. Nanjing: Southeast University Press.

[8] Zhang, Zongxiang. 1964. On Huang Binhong's Paintings. In A Collection of Works in Art Circles (Vol. 5). Hong Kong: The Commercial Press.

[9] Zheng, Yimei. 2005a. Stories of Modern Celebrities. Beijing: Zhonghua Book Company.

[10] Zheng, Yimei. 2005b. The Scattered Leaves in the Art Circles. Beijing: Zhonghua Book Company.

[11] Zheng, Yimei. 2005c. Interesting Sidelights in the Literary Circle. Beijing: Zhonghua Book Company.

[12] Zhu, Boxiong. 1999. An almost Forgotten Great Master of the "Shanghai School" - Pu Hua. Forum of Arts. 1: 3036. 